\title{
A HIGHLY EFFICIENT SYNTHESIS OF SUBSTITUTED IMIDAZOLES VIA A ONE-POT MULTICOMPONENT REACTION BY USING UREA/HYDROGEN PEROXIDE (UHP)
}

\author{
ALI MALEKI*AND ZAHRA ALIREZVANI \\ Catalysts and Organic Synthesis Research Laboratory, Department of Chemistry, Iran University of Science and Technology, \\ Tehran 16846-13114, Iran
}

\begin{abstract}
A simple, versatile and highly efficient synthesis of 2,4,5-trisubstituted imidazoles by a condensation reaction of benzil or benzoin, aldehydes and ammonium acetate in the presence of urea/hydrogen peroxide (UHP) as a mild and efficient molecular catalyst in refluxing ethanol is described. The present methodology offers several advantages such as green protocol, inexpensive catalyst, high-to-excellent yields, and simple and easy work-up procedure.
\end{abstract}

Key words: Multicomponent reaction, imidazole, benzil, urea, hydrogen peroxide.

\section{INTRODUCTION}

Multicomponent reactions (MCRs) allow the assembly of complex molecules in a one-pot process and show a facile execution, high atomeconomy and high selectivity. MCRs usually afford good-to-high yields, deserve simple work-up procedure and are fundamentally different and more efficient than classic two-component and stepwise reactions [1].

The chemistry of tri- and tetra-substituted $1 H$-imidazoles has been reviewed recently [2]. In recent years, alkylated imidazoliums are substantially used in ionic liquids that have been given a new approach to environmentally- benign and green chemistry. Imidazoles are one of the most important fivemembered ring heteroaromatic nitrogen-bearing compounds that show a broad range of pharmaceutical and industrial applications. Imidazole cores are present in many compounds with pronounced biologic activities such as angiotensin inhibitors [3], anti-inflammatory [4], glucagon antagonist [5], antiviral [6], antimicrobial [7], fungicidal, and high cytotoxicity, which have indicated them as new candidates in cancer therapy [8]. The structures of some of the commercial imidazole-core drugs including Cimetidine (I), Trifenager (II) and Ketoconazole (III) are shown in Figure 1.<smiles>CN=C(NC)NCCSCc1c[nH]cn1</smiles>

(I)<smiles>CN(C)CCOc1ccccc1-c1nc(-c2ccccc2)c(-c2ccccc2)[nH]1</smiles>

(II)<smiles>CC1(c2ccc(Cl)cc2Cl)OC[C@@H](CO)O1</smiles>

(III)

Figure 1. The structures of some of the commercial imidazole-core drugs.

This versatile applicability highlights the importance of access to efficient synthetic routes to well-designed highly substituted imidazole derivatives. A number of methods have been developed for the synthesis of 2,4,5-trisubstituted imidazoles. Some of these synthetic methods are associated with one or more serious disadvantages such as tedious and complex work-up and purification procedures, significant amounts of waste materials, occurrence of side reactions, long reaction times, low yields and the use of expensive reagents. Therefore, the development of simple, efficient, clean, high-yielding, and environmentally friendly approaches using new catalysts for the synthesis of highly substituted imidazoles is of prime importance.

In continuation of our interest in the application of new catalysts in MCRs [9], herein, an efficient synthesis of highly substituted imidazoles $\mathbf{4}$ has been developed by a condensation of benzil $\mathbf{1}$ or benzoin $\mathbf{2}$, various substituted aldehydes $\mathbf{3}$ and ammonium acetate using urea/hydrogen peroxide (UHP) as an efficient catalyst in refluxing ethanol under mild reaction conditions in excellent yields (Scheme 1). As an important output of this work, UHP is introduced as an efficient, inexpensive and mild homogenous catalyst in the synthesis of substituted imidazoles.<smiles>[R]c1nc(-c2ccccc2)c(-c2ccccc2)[nH]1</smiles>

Scheme 1. Synthesis of 2,4,5-trisubstituted imidazoles catalyzed by UHP.

\section{RESULTS AND DISCUSSION}

To find the optimum conditions, a systematic study considering different variables affecting the reaction yield was carried out for the reaction of benzil or benzoin, 4-chlorobenzaldehyde and $\mathrm{NH}_{4} \mathrm{OAc}$ (molar ratio: 1:1:4, respectively) as a model reaction. The results are summarized in the Table 1. 
Table 1. Optimization of the model reaction conditions. ${ }^{\mathrm{a}}$

\begin{tabular}{|c|c|c|c|c|c|c|}
\hline \multirow{2}{*}{ Entry } & \multirow{2}{*}{$\begin{array}{c}\text { Catalyst loading } \\
\%)\end{array}$} & \multirow{2}{*}{ Solvent } & \multirow{2}{*}{ Temp. $\left({ }^{\circ} \mathrm{C}\right)$} & \multirow{2}{*}{ Time (h) } & \multicolumn{2}{|c|}{ Yield $^{\mathrm{b}}(\%)$} \\
\hline & & & & & Benzil & Benzoin \\
\hline 1 & - & - & r.t. & 24 & - & - \\
\hline 2 & - & EtOH & r.t. & 24 & Trace & Trace \\
\hline 3 & - & $\mathrm{H}_{2} \mathrm{O}$ & Reflux & 10 & Trace & Trace \\
\hline 4 & - & $\mathrm{EtOH}$ & Reflux & 7 & 35 & 20 \\
\hline 5 & - & $\mathrm{EtOH}$ & 60/ultrasonic & 8 & 30 & 19 \\
\hline 6 & 1 & $\mathrm{EtOH}$ & Reflux & 4 & 51 & 40 \\
\hline 7 & 2 & $\mathrm{EtOH}$ & Reflux & 4 & 57 & 45 \\
\hline 8 & 5 & EtOH & Reflux & 4 & 79 & 70 \\
\hline 9 & 10 & $\mathrm{EtOH}$ & Reflux & 2 & 95 & 90 \\
\hline 10 & 20 & $\mathrm{EtOH}$ & Reflux & 3 & 80 & 69 \\
\hline 11 & 10 & $\mathrm{CH}_{3} \mathrm{CN}$ & Reflux & 2 & 40 & 31 \\
\hline 12 & 10 & - & 120 & 5 & 56 & 49 \\
\hline
\end{tabular}

${ }^{a}$ Reaction conditions: 4-chlorobenzaldehyde ( $\left.1 \mathrm{mmol}\right)$, benzil or benzoin $(1 \mathrm{mmol})$, ammonium acetate $(4 \mathrm{mmol})$, EtOH (3 mL) and UHP.

${ }^{\mathrm{b}}$ The yields refer to the isolated product.

According to the results indicated in Table 1, the products were obtained in higher yields in refluxing EtOH. By using $\mathrm{H}_{2} \mathrm{O}$ as a solvent lower yield was obtained in $10 \mathrm{~mol} \%$ loading of UHP as an organic and water soluble catalyst. It may be explained by the weakness of hydrogen bonding between urea and hydrogen peroxide in the presence of $\mathrm{H}_{2} \mathrm{O}$.

In order to optimize the reaction conditions, diverse imidazole derivatives 4a-n were prepared from the one-pot reaction of benzil 1 or benzoin $\mathbf{2}$, various aldehyde $\mathbf{3}$ and ammonium acetate in the presence of a catalytic amount of UHP (10 mol\%) in refluxing EtOH. The results are summarized in Table 2.
A possible mechanism for the synthesis of imidazole derivatives 4a-n in the presence of UHP is shown in Scheme 2. In both of the directions, the UHP promotes the dissociation of ammonium acetate to ammonia is required for the initial imine condensation. Then, UHP oxidizes benzoin to benzil. So, the mechanism may proceed through two paths when benzoin was used as a starting material. On the other hand, UHP has activated carbonyl groups for nucleophilic attack through hydrogen bonding.

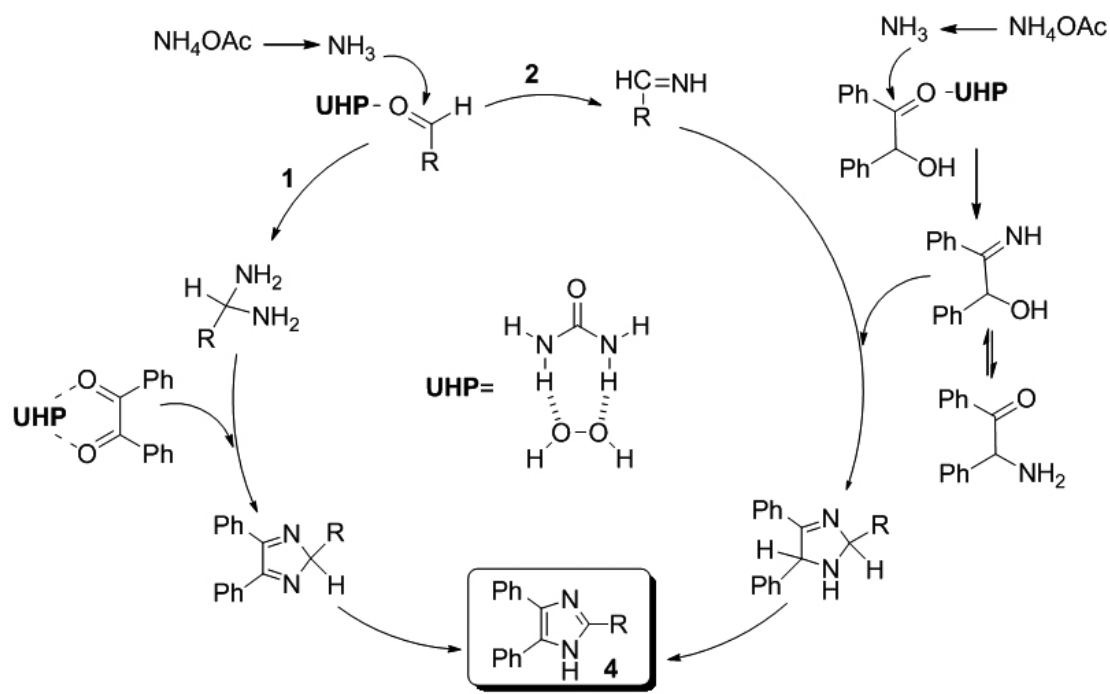

Scheme 2. Suggested mechanism of the synthesis of $\mathbf{4 a - n}$.

In summary, a rapid, highly efficient, one-pot and selective synthesis of fully substituted imidazoles has been developed by the condensation reaction of benzil or benzoin, various substituted aldehydes and ammonium acetate in the presence of a catalytic amount of urea/hydrogen peroxide in refluxing ethanol under mild reaction conditions in suitable times and good-to-excellent yields.

\section{Experimental section}

General procedure for the synthesis of imidazole derivatives 4a-n

A mixture of benzil or benzoin $(1.0 \mathrm{mmol})$, an aldehyde $(1.0 \mathrm{mmol})$, $\mathrm{NH}_{4} \mathrm{OAc}(4.0 \mathrm{mmol})$ and UHP $(10 \mathrm{~mol} \%)$ was carried out in refluxing EtOH.
The progress of the reaction was monitored by TLC. After completion of the reaction, it was stopped and the crude product was isolated by filtration of the reaction mixture and washing of the precipitate with $\mathrm{H}_{2} \mathrm{O}$. Pure products $4 \mathbf{a}-\mathbf{n}$ were obtained via re-crystallization by EtOH.

Chemical characterization data of 4,5-diphenyl-2-p-tolyl-1Himidazole (4i)

MP: $231-233{ }^{\circ} \mathrm{C}$; FT-IR $\left(\mathrm{KBr}, \mathrm{cm}^{-1}\right): 3033,1600,1496,1446,825,767$ 696; ${ }^{1} \mathrm{H}$ NMR (500 MHz, $\left.\mathrm{CDCl}_{3}\right): \delta(\mathrm{ppm}) ; 2.39(\mathrm{~s}, 3 \mathrm{H}), 7.23-7.74(\mathrm{~m}, 12 \mathrm{H})$, 7.78-7.79 (d, $2 \mathrm{H}), 9.64(\mathrm{~s}, 1 \mathrm{H}) ;{ }^{13} \mathrm{C}$ NMR $\left(125 \mathrm{MHz}, \mathrm{CDCl}_{3}\right): \delta(\mathrm{ppm}) ; 21.8$, $125.6,127.59,128.23,129.0,130.0,139.2,146.6$. 


\section{ACKNOWLEDGEMENTS}

We are grateful for the financial support from the Research Council of the Iran University of Science and Technology, Tehran, Iran.

\section{Supplementary data}

Supplementary data associated with this article can be found, in the online version.

Table 2. Synthesis of imidazole derivatives 4a-n in the presence of UHP. ${ }^{\text {a }}$

\begin{tabular}{|c|c|c|c|c|c|}
\hline \multirow{2}{*}{ Entry } & \multirow{2}{*}{ Product } & \multirow{2}{*}{ Time (h) } & \multicolumn{2}{|c|}{ Yield $^{\mathrm{b}}(\%)$} & \multirow{2}{*}{ Melting point ${ }^{\mathrm{c}}\left({ }^{\circ} \mathrm{C}\right)$} \\
\hline & & & Benzil & enzoin & \\
\hline 1 & & 2 & 95 & 90 & $265-267$ \\
\hline 2 & & 4 & 88 & 78 & $214-216$ \\
\hline 3 & & 2 & 92 & 88 & $255-257$ \\
\hline 4 & & 3 & 88 & 79 & $187-189$ \\
\hline 5 & & 2 & 95 & 92 & $265-266$ \\
\hline 6 & & 3 & 85 & 80 & $226-229$ \\
\hline 7 & & 4 & 88 & 79 & $249-251$ \\
\hline 8 & & 3.5 & 82 & 76 & $264-265$ \\
\hline 9 & & 3.5 & 89 & 80 & $231-233$ \\
\hline 10 & & 3 & 88 & 80 & $230-231$ \\
\hline 11 & & 4.5 & 89 & 83 & $233-234$ \\
\hline 12 & & 4 & 90 & 85 & $256-258$ \\
\hline 13 & & 4 & 88 & 76 & $174-176$ \\
\hline 14 & & 4.5 & 87 & 79 & $164-165$ \\
\hline
\end{tabular}

${ }^{a}$ Reaction conditions: benzoin or benzil $(1 \mathrm{mmol})$, aldehyde ( $\left.1 \mathrm{mmol}\right)$, ammonium acetate $(4 \mathrm{mmol})$, EtOH ( $3 \mathrm{~mL}$, reflux $)$ and UHP (10 mol\%).

${ }^{\mathrm{b}}$ The yields refer to isolated product.

${ }^{c}$ All compounds were known and their structures were established from their spectral data and melting points as compared with literature values. 


\section{REFERENCES}

1. A. Dömling, W. Wang, K. Wang, Chem. Rev. 112, 3083, (2012).

2. M. M. Heravi, M. Daraie, V. Zadsirjan, Mol. Divers. 19, 577, (2015); and the references cited therein.

3. A. D. Palkowitz, M. I. Steinberg, K. J. Thrasher, J. K. Reel, K. L. Hauser, K. M. Zimmerman, S. A. Wiest, C. A. Whitesitt, R. L. Simon, J. Med. Chem. 37, 4508, (1994).

4. J. I. Trujillo, J. R. Kiefer, W. Huang, A. Thorarensen, L. Xing, N. L. Caspers, J. E. Day, K. J. Mathis, K. K. Kretzmer, B. A. Reitz, Bioorg. Med. Chem. Lett. 19, 908, (2009).

5. L. L. Chang, K. L. Sidler, M. A. Cascieri, S. de Laszlo, G. Koch, B. Li, M. MacCoss, N. Mantlo, S. O’Keefe, M. Pang, A. Rolando, W. K. Hagmann, Bioorg. Med. Chem. Lett. 11, 2549, (2011).

6. D. Sharma, B. Narasimhan, P. Kumar, V. Judge, R. Narang, E. De Clercq, J. Balzarini, Eur. J. Med. Chem. 44, 2347, (2009).
7. S. Kumar, J. Boehm, J. C. Lee, Nature Rev. Drug Disc. 2, 717, (2003).

8. A. J. King, D. R. Patrick, R. S. Batorsky, M. L. Ho, H. T. Do, S. Y. Zhang, R. Kumar, D. W. Rusnak, A. K. Takle, D. M. Wilson, Cancer Res. 66, 11100, (2006).

9. (a) A. Maleki, Tetrahedron 68,7827 , (2012). (b) A. Maleki, Tetrahedron Lett. 54, 2055, (2013). (c) A. Maleki, Helv. Chim. Acta. 97, 587, (2014). (d) A. Maleki, N. Ghamari, M. Kamalzare, RSC Adv. 4, 9416, (2014). (e) A. Maleki, M. Kamalzare, Catal. Commun. 53, 67, (2014). (f) A. Maleki, M. Kamalzare, Tetrahedron Lett. 55, 6931, (2014). (g) A. Maleki, R. Paydar, RSC Adv. 5, 33177, (2015). (h) A. Maleki, Z. Alrezvani, S. Maleki, Catal. Commun. 69, 29, (2015). (i) A. Maleki, H. Movahed, R. Paydar, RSC Adv. 6, 13657, (2016). 